\title{
Genetic variation of some quantitative traits in ten exotic varieties of silkworm, Bombyx mori L.
}

Md. Kamrul Ahsan and S.M. Rahman

Department of Zoology, University of Rajshahi, Rajshahi-6205, Rajshahi.

\begin{abstract}
An investigation was conducted with ten exotic varieties of silkworm, Bombyx mori L. to estimate variability, heritability and genetic advance for nine quantitative characters. A wide range of variation was observed for the majority of the traits and a major portion of the total phenotypic variation was of genetic in nature. The maximum phenotypic and genotypic coefficient of variation was found in filament length $(21.45,21.44)$ and the minimum in hatching percentage $(1.52,1.44)$, respectively. A moderate to high heritability was recorded for these varieties. Filament length showed the highest heritability (99.98). A comparatively high heritability accompanied by a high genetic advance was also noted for majority of the traits. Substantial variability, high heritability and high genetic advance for filament length, weight of mature larvae, total number of eggs laid per female and effective rate of rearing by weight recorded in this study would afford scope for effective selection.
\end{abstract}

Key words: Bombyx mori, genetic variation, exotic varieties.

\section{Introduction}

Collection of varietal materials of mulberry silkworm, Bombyx mori L. and their evaluation is a pre-requisite for the improvement of the economic traits (Akanda et al., 1998, Ahsan \& Rahman, 2008). But very little attention has so far been given for the improvement of mulberry silkworm in Bangladesh. The detailed genetic analysis of quantitative characters of the available varieties of $B$. mori has not been investigated till to date although studies on the variation of yield and yield contribution characters are of great importance for the improvement of silk yield (Rahman \& Khalequzzaman, 1993; Reza \& Rahman, 1996, 2005). The progress and success in any breeding programme for evolving superior breeds depends upon the nature and magnitude of genetic variability in the available materials. If the variability in the population of largely in genetic nature with least environmental effect, the probability of isolating superior genotype is high. Since this variability is highly influenced by the environment, it becomes difficult to predict the contribution of genetic factors against environmental effects. With this back ground, the present investigation was undertaken to study the genetic variability among ten exotic stocks available in Bangladesh.

\section{Materials and methods}

Ten exotic varieties of silkworm namely, Dong 34(M), Ziangsu - 12(J), RB - 001, RB - 112, Bivoltine - $\mathrm{J}, \mathrm{NB}_{7}, \mathrm{NB}_{18}, \mathrm{NB}_{4} \mathrm{D}_{4}, \mathrm{SK}_{1}$ and $\mathrm{SK}_{2}$ selected from Bangladesh Sericulture Research and Training Institute, Rajshahi constituted the base material of this experiment. Standard rearing techniques recommended by Krishnaswami (1978) were followed. Disease free layings (dfls) from each breed were reared on rearing trays in a randomized block design with three replications. Nine quantitative characters such as total number of eggs laid per female (TEL), hatching percentage (HP), weight of mature larvae (LW), effective rate of rearing by number (ERRn), effective rate of rearing by weight (ERRW), cocoon weight $(\mathrm{CW})$, shell weight (SW), filament length $(\mathrm{FL})$ and estimated cocoon yield per $100 \mathrm{dfls}$ (ECY) were collected from each replication for statistical analysis. Genotypic $\left(\delta^{2} \mathrm{~g}\right)$ and phenotypic $\left(\delta^{2} p\right)$ variations were estimated by the formula given by Burton \& De Vane (1953) and the coefficient of variability was worked out as described by Burton (1952). Heritability in broad sense was estimated by the following formula given by Hanson et al. (1956).

Heritability (Broad sense) $=\delta^{2} g / \delta^{2} p \times 100$

The expected genetic advance was estimated by the following formula:

Genetic advance (GA) $=\delta^{2} \mathrm{~g} / \delta^{2} \mathrm{p} \times \mathrm{k} \sqrt{\delta^{2}} \mathrm{p}$.

Where $k$ has a value of 2.06 which is the expectation in $5 \%$ selection intensity from a large population (Lush, 1949; Miller et al., 1958) 


\section{Results and Discussion}

Analyses of variances of nine quantitative characters are shown in Table1. The genotype items showed highly significant results indicating pronounced racial diversity have been substantiated by the finding of Tayade 1987, Ahsan et al., 2001; Reza \& Rahman, 2005. Similar results on varietal differences with respect to larval and cocoon characters in $B$. mori have been reported by Sidhu et al. (1969), Ahsan et al. (1998) and to larval characters by Reza et al. (1993). The replication items revealed insignificant results showing homogeneity in different parts of the present investigation.

The results on overall range, mean with SE and genetic variability for different characters are shown in Table 2. Phenotypic variances $\left(\delta^{2} p\right)$ were generally greater than their corresponding genotype $\left(\delta^{2} \mathrm{~g}\right)$ or environmental $\left(\delta^{2} \mathrm{e}\right)$ variances in all the cases. Closer $\delta^{2} p$ and $\delta^{2} g$ as well as higher $\delta^{2} \mathrm{~g}$ than $\delta{ }^{2} \mathrm{e}$ for all the characters indicated that the major part of the phenotypic variation was of genotypic in nature.

Estimates on phenotypic (CVp), genotypic ( $C V g)$ and environmental (CVe) co-efficient of variability, heritability $\left(H_{b}\right)$, genetic advance (GA) and genetic advance as percentage of mean (GA\%) have been presented in Table3. The maximum phenotypic and genotypic coefficient of variation was found in filament length and the minimum in hatching percentage. The range of phenotypic coefficient of variation was from $1.52-21.45$ and of genotypic was 1.44 - 21.44. Where as the highest environmental coefficient of variation was recorded in estimated cocoon yield / 100 dfls
(5.38) and lowest in shell weight (0.15). The genotypic coefficient of variation alone is not sufficient to determine the amount of variation which is heritable. The heritable portion of variation can be found from heritability estimates and genetic gain (Johnson et al., 1955). In this study the highest heritability $\left(\mathrm{H}_{\mathrm{b}}\right)$ was obtained for FL (99.89) followed by LW, TEL, FRRW, CW, HP, FRRn, SW and lowest in ECY (72.29). The genetic advance (GA) estimated for different characters ranged from 0.087 (SW) - 363.45 (FL). When genetic advance was expressed as percentage of respective means (GA\%), highest score was noted in FL (44.15) followed by SW, LW, TEL, ERRw, CW, ECY, ERRn and lowest in $\mathrm{HP}(2.82)$.

In this results FL, LW, TEL and ERRw showed comparatively high coefficient of variability, heritability, as well as genetic advance and genetic advance as percentage of mean indicates that a wide range of genetic diversity existed which could be used in a breeding programme. It also indicated the importance of additive gene effects in these characters and phenotypic selection of these characters would be effective (Panse, 1957; Rahman \& Rahman, 1990; Reza et al., 1993).

A number of characters showed high heritability but low genetic advance. This might happen due to the intra or inter allelic interaction. In such situation recurrent selection may be adopted to these trails (Pershad et al., 1986, Rahman \& Rahman, 1990; Ahsan \& Rahman 2008).

Table 1. Mean square of ANOVA for nine quantitative characters in B. mori.

\begin{tabular}{|c|c|c|c|c|c|c|c|c|c|c|}
\hline & \multicolumn{10}{|c|}{ df MS } \\
\hline & & TEL & $\mathrm{HP}$ & LW & ERRn & ERRw & CW & SW & FL & ECY \\
\hline Variety & 9 & 6943.63 & 5.35 & $1.47^{x}$ & $6.48^{\pi x}$ & $182.24^{x}$ & $0.0422^{\text {xx }}$ & $0.00656^{\times 1}$ & $93521.05^{*}$ & 17.38 \\
\hline Replication & 2 & 14.09 & 0.02 & 0.0039 & 0.025 & 0.67 & 0.0002 & 0.00049 & 24.62 & 2.73 \\
\hline Error & 8 & 18.64 & 0.19 & 0.0037 & 0.27 & .097 & 0.00037 & 0.00035 & 34.56 & 1.97 \\
\hline
\end{tabular}

** $p<0.001$

Table 2. Range, Mean with SE and components of variance of different characters in B. mori.

\begin{tabular}{l|l|llllll}
\hline Characters & Range & Mean & SE & $\delta^{2} p$ & $\delta^{2} \mathrm{~g}$ & $\delta^{2} \mathrm{e}$ \\
\hline TEL & $445.17-70.18$ & 518.35 & 3.53 & 2326.97 & 2308.33 & 18.64 \\
HP & $88.50-94.00$ & 91.02 & 0.35 & 1.91 & 1.72 & 0.19 \\
LW & $3.25-5.00$ & 4.16 & 0.05 & 0.4925 & 0.4888 & 0.0037 \\
ERRn & $64.00-69.51$ & 66.25 & 0.42 & 2.34 & 2.07 & 0.27 \\
ERRW & $76.52-97.40$ & 87.76 & 0.50 & 61.39 & 60.42 & 0.97 \\
CW & $1.14-1.46$ & 1.33 & 0.0157 & 0.01431 & 0.01394 & 0.00037 \\
SW & $0.17-0.29$ & 0.233 & 0.0153 & 0.00242 & 0.00207 & 0.00035 \\
FL & $605.17-1000$ & 823.28 & 4.8 & 31196.72 & 31162.16 & 34.56 \\
ECY & $19.28-29.58$ & 26.08 & 1.15 & 7.11 & 5.14 & 1.97 \\
\hline
\end{tabular}


Table 3. Phenotypic $\left(\mathrm{CV}_{\mathrm{P}}\right)$, genotypic $(\mathrm{CVg})$ and environmental $(\mathrm{CVe})$ coefficient of variation, heritability $\left(\mathrm{H}_{\mathrm{b}}\right)$, genetic advance (GA) and genetic advance as percentage of means (GA\%) of different characters in B. mori.

\begin{tabular}{lcccccc}
\hline Characters & CVp & CVg & CVc & Hb & GA & GA\% \\
\hline TEL & 9.31 & 9.27 & 0.83 & 99.20 & 98.58 & 19.02 \\
HP & 1.52 & 1.44 & 0.48 & 90.05 & 2.54 & 2.82 \\
LW & 16.87 & 16.81 & 1.46 & 99.25 & 1.43 & 34.49 \\
ERRn & 2.31 & 2.17 & 0.78 & 88.46 & 2.79 & 4.21 \\
ERRw & 8.93 & 8.85 & 1.12 & 98.42 & 15.89 & 18.10 \\
CW & 8.99 & 8.88 & 1.45 & 97.41 & 0.24 & 18.05 \\
SW & 21.11 & 19.53 & 0.15 & 85.54 & 0.087 & 37.20 \\
FL & 21.45 & 21.44 & 0.71 & 99.89 & 363.45 & 44.15 \\
ECY & 10.22 & 8.69 & 5.38 & 72.29 & 3.97 & 15.25 \\
\hline
\end{tabular}

\section{References}

Ahsan, M.K. \& Rahman, S.M. 2008. Genetic variability and correlation analysis in hybrids of silkworm, Bombyx mori L. for egg characters. Univ. j. zoo/. Rajshahi Univ. 27:13-16.

Ahsan, M.K., Rahman, S.M., Haque, M.T. \& Ali, I.A. 2001. Interrelationship between some egg and larval characters in different breeds of silkworm, Bombyx mori L. Univ. J. Zoo/. Rajshahi Univ. 20:81-84.

Ahsan, M.K., Rahman, S.M. \& Ali, I.A. 1998. Inheritance of some quantitative traits in fifteen indigenous varieties of silkworm, Bombyx mori L. Univ. j. zoo/. Rajshahi Univ. 18:79-83.

Akanda, M.A.L., Alam, M.S. \& Uddin, M.M. 1998. Genetic variability, correlation and path analysis in composite maize. Bangladesh J. Agri. Res. 23(1): 107-113.

Burton, G.W., 1952. Quantitative inheritance in grass. Proc. 6th Inter. Grassland Cong. 1:277-283.

Burton, G.W. \& De Vane, E.H. 1953. Estimating heritability in tall fescue (Fescuta arundinaceae) from replicated clonal materials. Agron. J. 45:579604.

Hanson, C.H., Robinson, H.F. \& Comstock, R.E. 1956. Biometrical studies of yield in segregation populations of Korean lespedeza. Agron. 48:268272.

Johnson, H.W., Robinson, H.F. \& Comstock, R.E. 1955. Estimates of genetic and environmental variability in soyabean. Agron. J. 47:314-318.

Krishnaswami S. 1978. New Technology of silkworm rearing. Central Silk Board, India. 23 pp.

Lush, J.L. 1949. Heritability of quantitative characters in farm animals. Heriditas (suppl.). 35:256 -287.

Miller, P.A., Williums, J.C., Robinson, H.F. \& Constock, R.E. 1958. Estimates of genotypic and environmental variances and co-variances in upland cotton and their implication in selection. Agron. J. 50:126-131.
Panse, V.G. 1957. Statistical methods for agricultural works. I.C.A.R., New Delhi..241 pp.

Pershad, G.D., Datta, R.K., Bhargave, S.K., Vijayakumar, H.V. \& Jolly, M.S. 1986. Performance of some multivoltine races of Bombyx mori L. Sericologia. 26:295-301.

Rahman, M.S. \& Rahman, S.M. 1990. Estimates of variability and some genetic parameters in eri silkworm, philosamia ricini Bosisd. Bangladesh. J. Zool. 18(2):239-244.

Rahman, S.M \& Khalequzzaman, M. 1993. Studies on variation in egg laying and some of its components in silkworm. B. mori 1,. Bangladesh J. Zool. 21(1):95-101.

Reza, A.M.S. \& Rahman, S.M. 1996. The genetic variability, heritability and genetic advance in silkworm, Bombyx mori L. Bangladesh. J. Agri. 21:1-6.

Reza, A.M.S. \& Rahman, S.M. 2005. Genetic parameters of some yield and yield contributing traits in silkworm, Bombyx mori L. Univ. j. zoo/. Rajshahi Univ. 24:55-58.

Reza. A.M.S, Rahman, M.S. \& Rahman, S.M. 1993. Studies on the variation of some larval traits in different breeds of silkworm, Bombyx mori L. Univ. j. zool. Rajshahi Univ. 12:21-24.

Sidhu, N.S., Singh, R.K., Pillai, V.S. \& Sreenivasan, R. 1969. Performance of some of the breeds of silkworm, Bombyx mori L. Silkworm Inf. Bull. 1: 41- 53

Tayade, D.S. 1987. Performance of different races of silkworm, Bombyx mori under Marathwada conditions. Sericologia. 27:381-389. 